\title{
Effect of Tb-doped Concentration Variation on the Electrical and Dielectric Properties of $\mathrm{CaF}_{2}$ Nanoparticles
}

\author{
Xiaoyan Cui ${ }^{1}$, Tingjing Hu ${ }^{1, *} \mathbb{C}^{\mathbb{D}}$, Jingshu Wang ${ }^{1}$, Xin Zhong ${ }^{1}$, Yinzhu Chen ${ }^{1}$, Junkai Zhang ${ }^{1}$, \\ Xuefei $\mathrm{Li}^{1}$, Jinghai Yang ${ }^{1}$ and Chunxiao Gao ${ }^{2}$ \\ 1 Key Laboratory of Functional Materials Physics and Chemistry of the Ministry of Education, \\ National Demonstration Center for Experimental Physics Education, Jilin Normal University, \\ Siping 136000, China; xycuimail@163.com (X.C.); jingshuwang126@126.com (J.W.); \\ zhongxin@calypso.cn (X.Z.); yinzhuchen126@126.com (Y.C.); junkaizhang126@126.com (J.Z.); \\ xuefeili163@163.com (X.L.); jhyang1@jlnu.edu.cn (J.Y.) \\ 2 State Key Laboratory of Superhard Materials, Jilin University, Changchun 130012, China; \\ chunxiaogao126@126.com \\ * Correspondence: tjhumars@126.com; Tel.: +86-434-3291986
}

Received: 29 June 2018; Accepted: 12 July 2018; Published: 14 July 2018

\begin{abstract}
Calcium fluoride $\left(\mathrm{CaF}_{2}\right)$ nanoparticles with various terbium $(\mathrm{Tb})$ doping concentrations were investigated by $\mathrm{X}$-ray diffraction (XRD), transmission electron microscopy (TEM), and alternating current $\left(\mathrm{AC}\right.$ ) impedance measurement. The original shape and structure of $\mathrm{CaF}_{2}$ nanoparticles were retained after doping. In all the samples, the dominant charge carriers were electrons, and the $\mathrm{F}^{-}$ ion transference number increased with increasing $\mathrm{Tb}$ concentration. The defects in the grain region considerably contributed to the electron transportation process. When the Tb concentration was less than $3 \%$, the effect of the ionic radius variation dominated and led to the diffusion of the $\mathrm{F}^{-}$ions and facilitated electron transportation. When the $\mathrm{Tb}$ concentration was greater than $3 \%$, the increasing deformation potential scattering dominated, impeding $\mathrm{F}^{-}$ion diffusion and electron transportation. The substitution of $\mathrm{Ca}^{2+}$ by $\mathrm{Tb}^{3+}$ enables the electron and ion hopping in $\mathrm{CaF}_{2}$ nanocrystals, resulting in increased permittivity.
\end{abstract}

Keywords: nanoparticles; electrical properties; dielectric behavior; transport process

\section{Introduction}

Lanthanide (III)-doped nanocrystals have attracted considerable attention due to their potential applications in electrical and optical devices [1-5]. Due to low refractivity, high transparency, and low phonon energy, fluoride compounds are well-known host materials for lanthanide (III)-doped nanocrystals [6-11]. As an important class of fluorides, calcium fluoride $\left(\mathrm{CaF}_{2}\right)$ has been used as a host due to its stability and non-hygroscopic behavior. Therefore, lanthanide (III)-doped $\mathrm{CaF}_{2}$ nanoparticles have been examined in fundamental and applied studies [12-17].

For optical and optoelectronic devices, energy consumption is a key factor in evaluating their performance [18-21]. Energy consumption is inextricably tied to the electrical and dielectric performance of the material used in a device. Therefore, the electrical and dielectric properties of lanthanide (III)-doped $\mathrm{CaF}_{2}$ nanoparticles are worth exploring. Due to the presence of numerous grain boundaries, nanocrystals have many unique properties that would not be present in their corresponding bulk counterparts [22,23]. Additionally, electrical and dielectric properties are closely related to the charge carrier types and their scattering processes. However, the above subjects have not been studied in detail. 
In this study, the morphology and structure of $\mathrm{CaF}_{2}$ nanoparticles with various $\mathrm{Tb}$ doping concentrations are studied using X-ray diffraction (XRD) and transmission electron microscopy (TEM). The electrical and dielectric properties are investigated using alternating current (AC) impedance measurements. The transportation properties of charge carriers are also discussed.

\section{Materials and Methods}

A series of $\mathrm{Tb}$-doped $\mathrm{CaF}_{2}$ nanoparticles were synthesized using the liquid-solid-solution (LSS) solvothermal route [24-26]. The sample was synthesized as follows: $16.8 \mathrm{~mL}$ oleic acid, $48 \mathrm{~mL}$ ethanol, and $0.4 \mathrm{~g}$ sodium hydroxide (Sinopharm Chemical Reagent Beijing Co., Ltd, Beijing, China) were mixed together and stirred for $10 \mathrm{~min} ; 1.888 \mathrm{~g} \mathrm{Ca}\left(\mathrm{NO}_{3}\right)_{2} \cdot \mathrm{H}_{2} \mathrm{O}$ (Sinopharm Chemical Reagent Beijing Co., Ltd, Beijing, China) dissolved in $20 \mathrm{~mL} \mathrm{H}_{2} \mathrm{O}$ was added to the solution and stirred for $10 \mathrm{~min}$. Then, $0.672 \mathrm{~g}$ sodium fluoride (NaF) (Sinopharm Chemical Reagent Beijing Co., Ltd, Beijing, China) dissolved in $20 \mathrm{~mL} \mathrm{H}_{2} \mathrm{O}$ was added to the solution and stirred for $1 \mathrm{~h}$. Finally, the solution was poured into an autoclave. The system was kept at $160{ }^{\circ} \mathrm{C}$ for $24 \mathrm{~h}$ and then cooled naturally in air. The product was centrifuged with cyclohexane (Sinopharm Chemical Reagent Beijing Co., Ltd, Beijing, China) and ethanol and dried at $80{ }^{\circ} \mathrm{C}$. To the Tb-doped samples, part of the $\mathrm{Ca}\left(\mathrm{NO}_{3}\right)_{2} \cdot \mathrm{H}_{2} \mathrm{O}$ was substituted by $\mathrm{Tb}\left(\mathrm{NO}_{3}\right)_{3} \cdot 5 \mathrm{H}_{2} \mathrm{O}$ (Sinopharm Chemical Reagent Beijing Co., Ltd, Beijing, China) and the $\mathrm{Tb}\left(\mathrm{NO}_{3}\right)_{3} \cdot 5 \mathrm{H}_{2} \mathrm{O}$ molar fractions were 1, 2, 3, 4, and $5 \mathrm{~mol} \%$. Transmission electron micrographs were measured by TEM (JEOL Ltd., Tokyo, Japan). The samples structure and phase were measured by XRD (Rigaku, Tokyo, Japan) with Cu K $\alpha$ radiation $(\lambda=1.5406 \AA$ ). The sample we synthesized was powered, which is incompact. However, to complete impedance measurements, the sample must be compact. Therefore, the sample was pressed into a cylinder $(\varnothing 6 \times 1 \mathrm{~mm})$ using a shock pressure (20 MPa). The impedance measurement was measured by parallel plate electrode at atmospheric pressure. The input voltage amplitude was $1 \mathrm{~V}$, and frequency ranged from 0.1 to $10^{7} \mathrm{~Hz}$. The output signal was gathered and processed by the impedance analyzer (Solartron 1260, Solartron, Hampshire, UK) with a dielectric interface (Solartron 1260, Solartron, Hampshire, UK).

\section{Results and Discussion}

Figure 1 shows the XRD patterns of the $\mathrm{Tb}$-doped $\mathrm{CaF}_{2}$ nanoparticles. The peaks of all the samples matched well with the standard cubic $\mathrm{CaF}_{2}$ phase (JCPDS Card No. 35-0816), and no impurity phase was found in the spectra. Therefore, the crystal structure remained unchanged after doping. Figures $2-4$ shows the TEM image, size distribution histogram, and energy dispersive spectrometer (EDS) of the $\mathrm{CaF}_{2}$ nanoparticles with various $\mathrm{Tb}$ concentrations. We observed that all samples were square and the mean dimensions were all about $12 \pm 3 \mathrm{~nm}$. The presence of Tb in the EDS spectrums of Tb-doped CaF 2 nanoparticles indicates that $\mathrm{Tb}$ was successfully doped into the samples. The impedance spectroscopy of $\mathrm{CaF}_{2}$ nanocrystals with various $\mathrm{Tb}$ concentrations is shown in Figure 5.

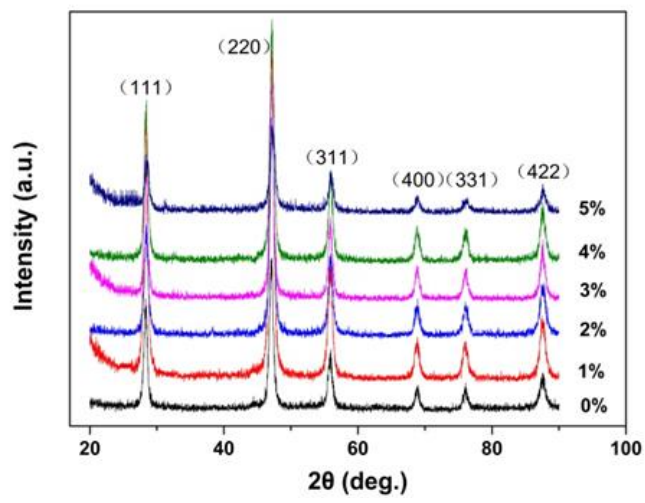

Figure 1. X-ray diffraction (XRD) patterns of terbium $(\mathrm{Tb})$-doped $\mathrm{CaF}_{2}$ nanocrystals. 


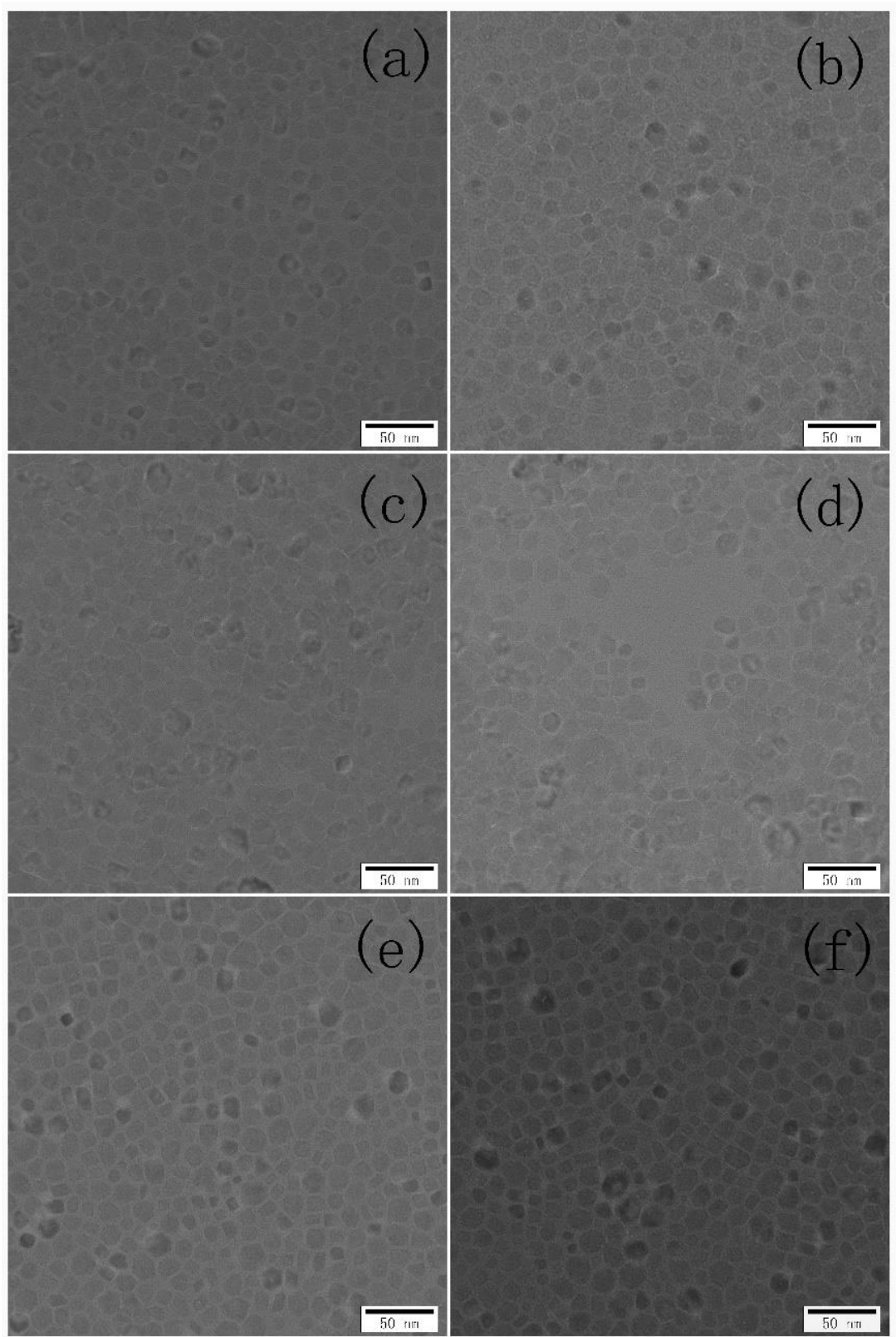

Figure 2. Transmission electron microscopy (TEM) image of the $\mathrm{CaF}_{2}$ nanoparticles with various $\mathrm{Tb}$ concentrations: (a) un-doped; (b) $1 \% \mathrm{~Tb}$; (c) $2 \% \mathrm{~Tb}$; (d) $3 \% \mathrm{~Tb}$; (e) $4 \% \mathrm{~Tb}$; and (f) $5 \% \mathrm{~Tb}$.
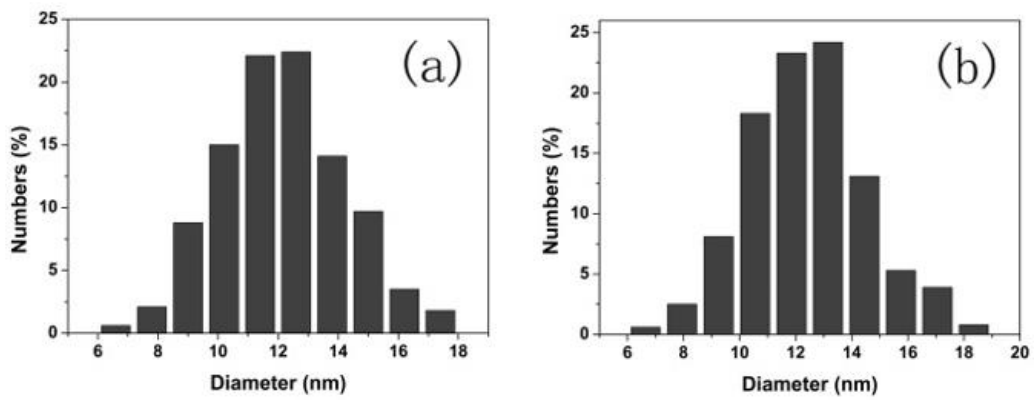

Figure 3. Cont. 

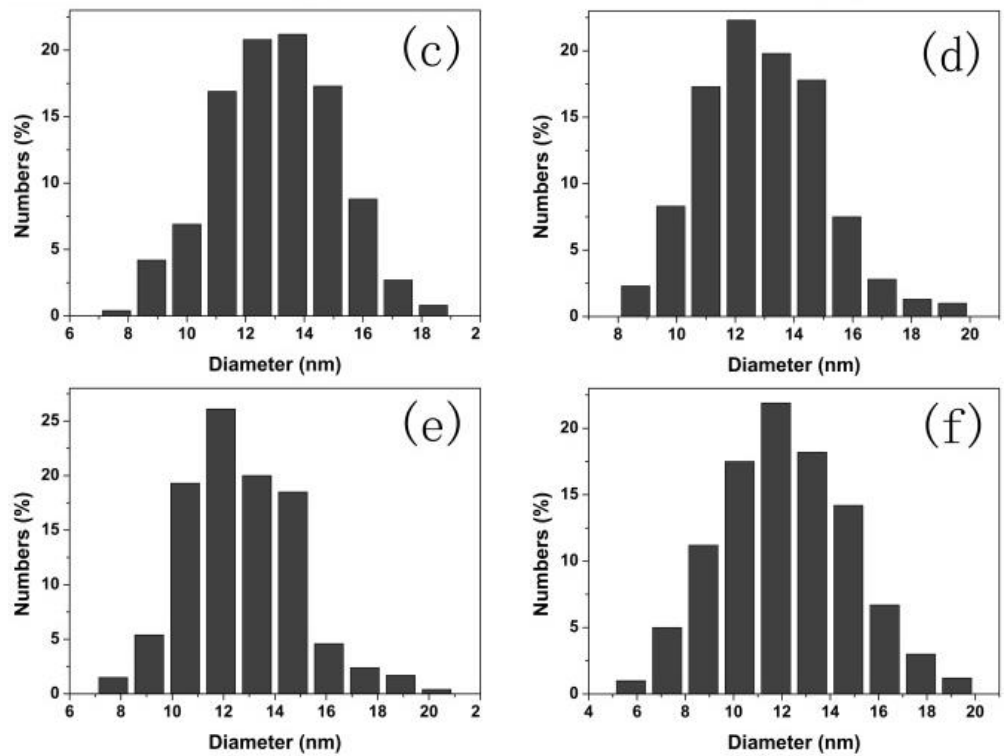

Figure 3. Size distribution histogram of the $\mathrm{CaF}_{2}$ nanoparticles with various $\mathrm{Tb}$ concentrations: (a) un-doped; (b) $1 \% \mathrm{~Tb}$; (c) $2 \% \mathrm{~Tb}$; (d) $3 \% \mathrm{~Tb}$; (e) $4 \% \mathrm{~Tb}$; and (f) $5 \% \mathrm{~Tb}$.

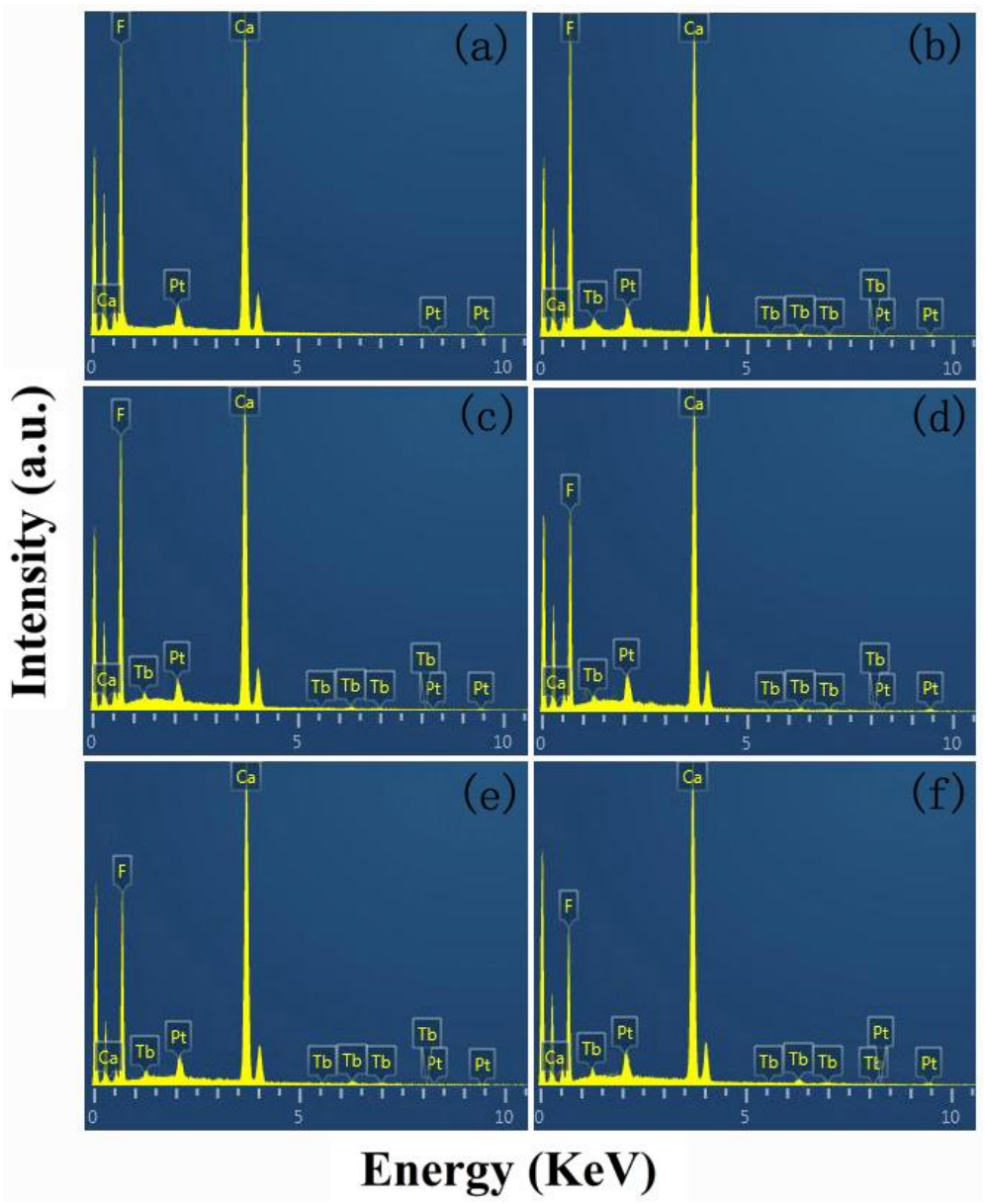

Figure 4. EDS spectrum of the $\mathrm{CaF}_{2}$ nanoparticles with various $\mathrm{Tb}$ concentrations: (a) un-doped; (b) $1 \% \mathrm{~Tb}$; (c) $2 \% \mathrm{~Tb}$; (d) $3 \% \mathrm{~Tb}$; (e) $4 \% \mathrm{~Tb}$; and (f) $5 \% \mathrm{~Tb}$. 

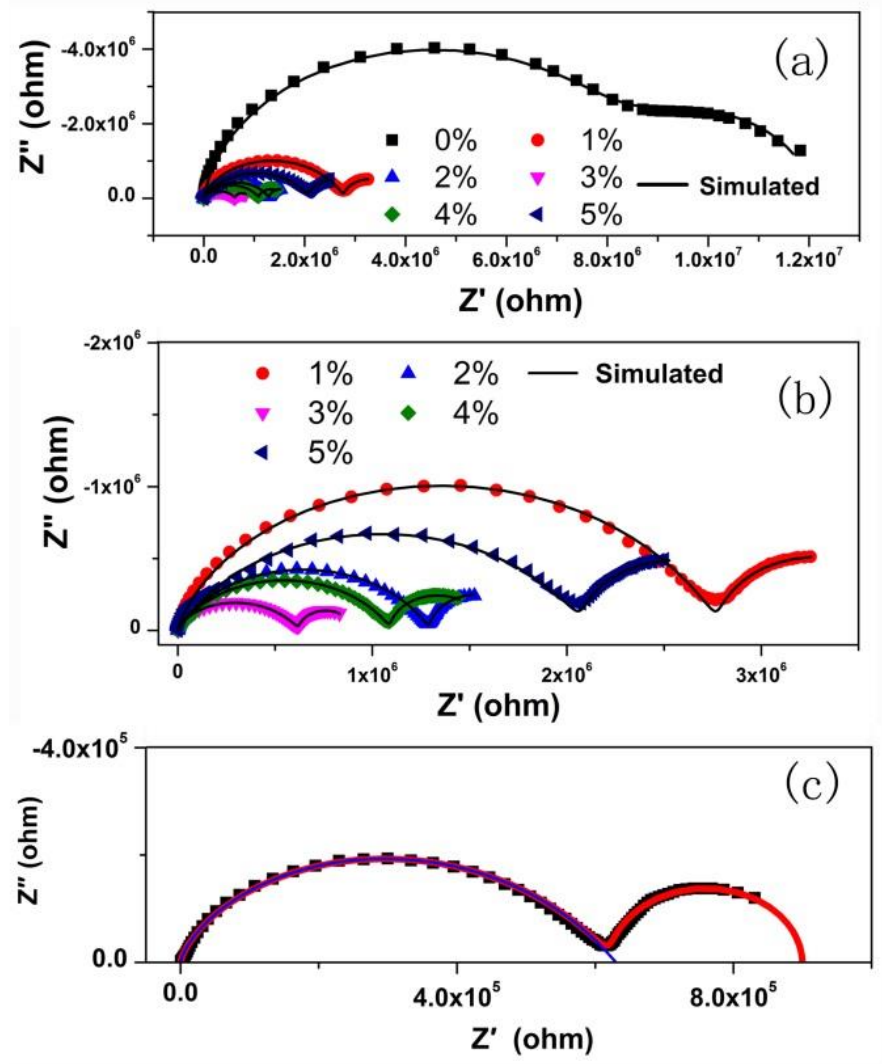

Figure 5. (a) The impedance spectroscopy of Tb-doped $\mathrm{CaF}_{2}$ nanocrystals; (b) The enlarged spectra with $\mathrm{Tb}$ concentrations ranging from $1 \%$ to $5 \%$; (c) The spectroscopy with $3 \% \mathrm{~Tb}$, where $R_{1}$ and $R_{2}$ are the $X$-axis intercepts of the spectroscopy.

To quantify the effect of $\mathrm{Tb}$ doping on the electrical transport properties of $\mathrm{CaF}_{2}$ nanocrystals, an equivalent circuit was used to fit the impedance results. The alternative representation $Z^{\prime} \sim \omega^{-1 / 2}$ was used to study the $\mathrm{F}^{-}$ion transport property and the result is presented in Figure 6.

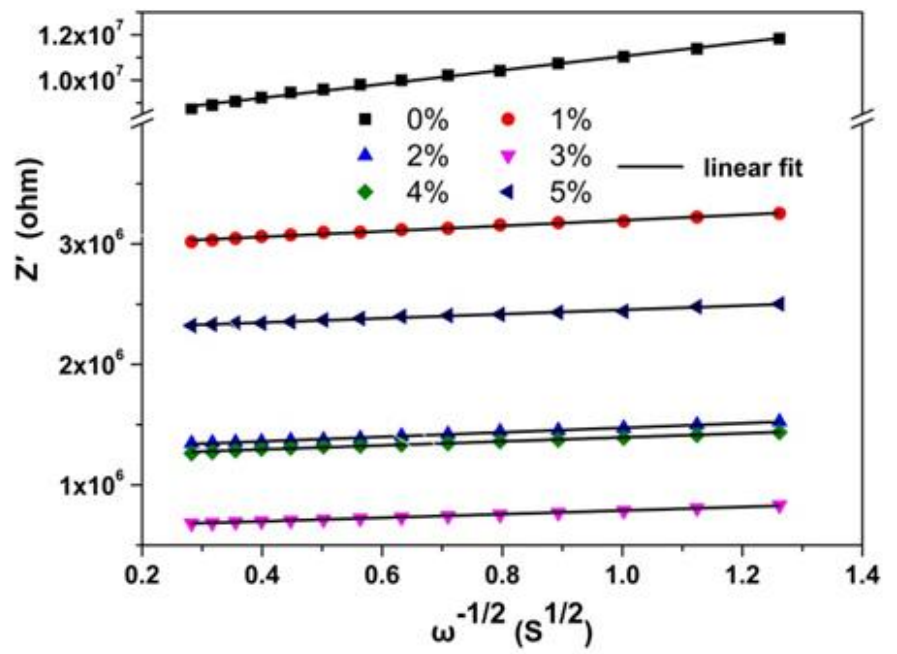

Figure 6. $Z^{\prime} \sim \omega^{-1 / 2}$ of $\mathrm{Tb}$-doped $\mathrm{CaF}_{2}$ nanocrystals in the low frequency region.

In the low frequency region, the $Z^{\prime}$ and $\omega^{-1 / 2}$ were linear, indicating the existence of $\mathrm{F}^{-}$ion diffusion at low frequency. Thus, a Warburg element was used to depict the $\mathrm{F}^{-}$ion conduction, 
which was added to the equivalent circuit diagram as presented in Figure 7. The fitted spectra agreed well with the experiment results (Figure 5), indicating that electron and ion conduction coexisted in the sample transport process.

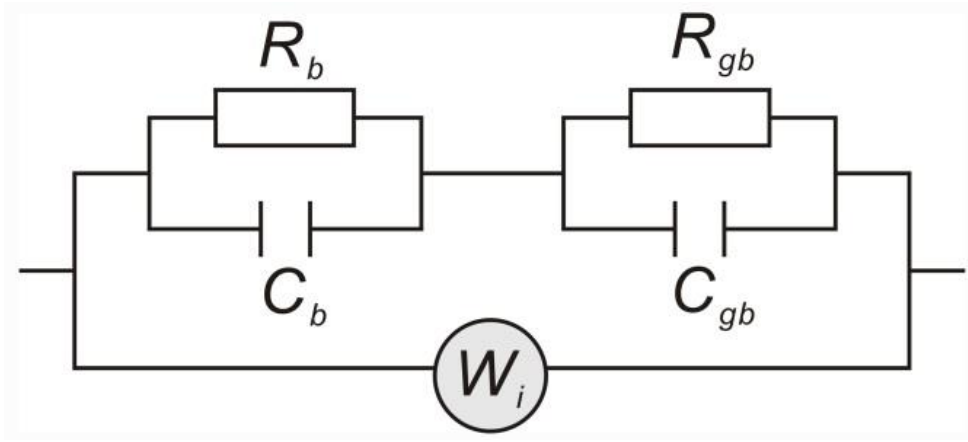

Figure 7. The equivalent circuit used to fit the impedance results. $R_{b}$ is grain resistance, $R_{g b}$ is grain boundary resistance, $C_{b}$ is grain capacitance, $C_{g b}$ is grain boundary capacitance, and $W_{i}$ is the Warburg impedance.

Considering the charge carriers include both ions and electrons, the transference number was used to describe the contribution of the ions and electrons to the transportation process [27]. The $\mathrm{F}^{-}$ ion transference number was defined as $t_{i}$ and electron as $t_{e}$, so $t_{i}$ and $t_{e}$ can be expressed as:

$$
\begin{gathered}
t_{i}=\left(R_{2}-R_{1}\right) / R_{2}, \\
t_{e}=R_{1} / R_{2},
\end{gathered}
$$

where $R_{1}$ and $R_{2}$ are the $X$-axis intercepts of the spectroscopy (Figure $5 \mathrm{c}$ ). The $t_{i}$ and $t_{e}$ of $\mathrm{CaF}_{2}$ nanocrystals with various $\mathrm{Tb}$ concentrations are presented in Figure 8. In all samples, the electron transport dominated, and the $\mathrm{F}^{-}$ion transference number increased with increasing $\mathrm{Tb}$ concentration.

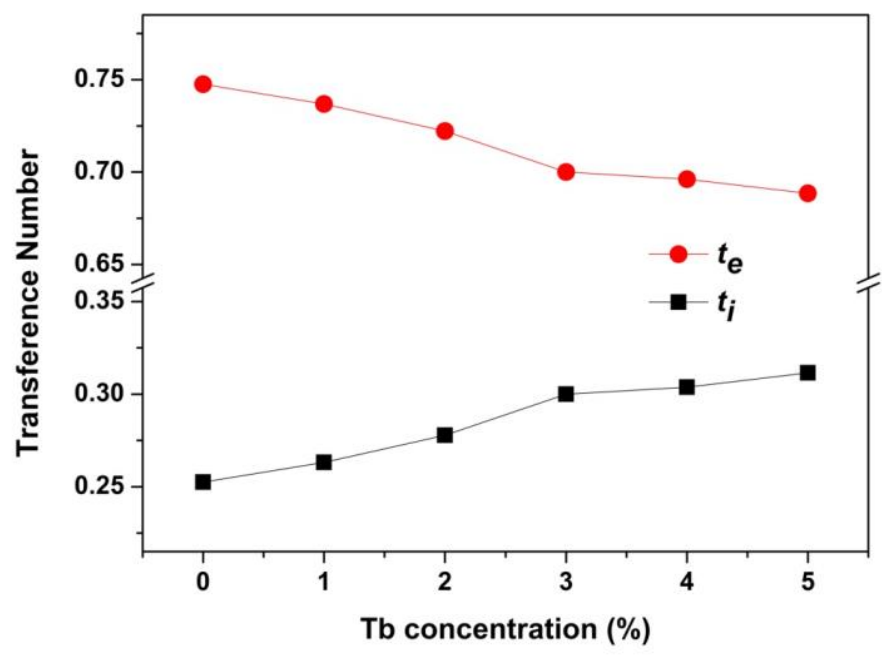

Figure 8. Tb concentration dependence of the ion transference number $\left(t_{i}\right)$ and the electron transference number $\left(t_{e}\right)$.

The Warburg coefficient $(\sigma)$ can be obtained by the following equation [28]:

$$
Z^{\prime}=Z_{0}^{\prime}+\sigma \omega^{-1 / 2},
$$


where $Z_{0}^{\prime}$ is a constant and $\omega$ is the frequency. By performing a linear fit on the $Z^{\prime} \sim \omega^{-1 / 2}$ scatterplot (Figure 6), the Warburg coefficient of $\mathrm{CaF}_{2}$ nanocrystals with different $\mathrm{Tb}$ concentrations was obtained. The ion diffusion coefficient can be expressed as:

$$
D_{i}=0.5\left(\frac{R T}{A F^{2} \sigma C}\right)^{2}
$$

where $R$ is the ideal gas constant, $T$ is temperature, $F$ is the Faraday constant, and $C$ is the molar concentration of $\mathrm{F}^{-}$ions. The $\mathrm{F}^{-}$ion diffusion coefficient for un-doped $\mathrm{CaF}_{2}$ nanocrystals was set as $D_{0}$, and the $D_{i} / D_{0}$ of various Tb concentrations was obtained, as shown in Figure 9a. Through fitting the impedance spectra by the equivalent circuit, the grain and grain boundary resistances were obtained as shown in Figure 9b.

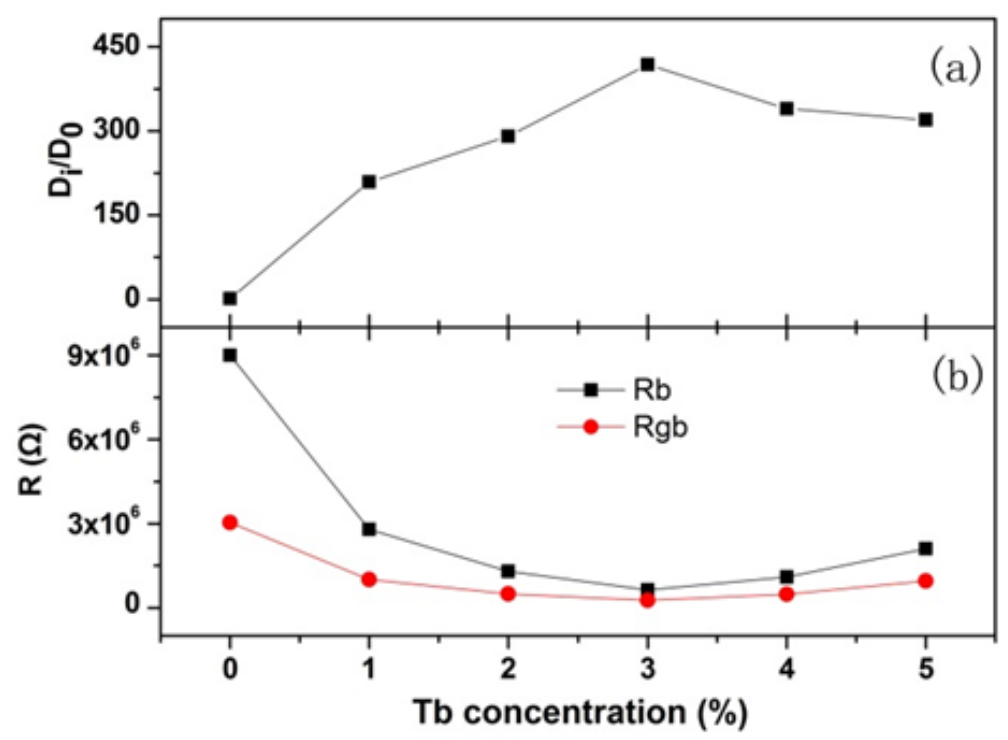

Figure 9. $\mathrm{Tb}$ concentration dependence of the diffusion coefficient (a), grain and grain boundary resistance $(\mathbf{b})$. $D_{0}$ represents the diffusion coefficient of un-doped $\mathrm{CaF}_{2}$ nanocrystals.

When the $\mathrm{Tb}$ concentration was less than $3 \%$, the $\mathrm{F}^{-}$ion diffusion coefficient increased with increasing $\mathrm{Tb}$ concentration; when the $\mathrm{Tb}$ concentration was greater than $3 \%$, the $\mathrm{F}^{-}$ion diffusion coefficient decreased. The grain and grain boundary resistances decreased with increasing $\mathrm{Tb}$ concentration until 3\%, and then increased. In all samples, the grain resistance dominated in the total resistance, indicating that the defects in the grain region considerably contribute to the electron transportation process.

The changing of the transport properties with the replacement of $\mathrm{Ca}^{2+}$ by $\mathrm{Tb}^{3+}$ was analysed from two aspects: (1) the $\mathrm{Tb}^{3+}$ ionic radius being smaller than the $\mathrm{Ca}^{2+}$ ionic radius, which leads to the increasing mobility of the charge carriers [29]; and (2) due to the different valence, the replacement of $\mathrm{Ca}^{2+}$ by $\mathrm{Tb}^{3+}$ results in the deformation of the lattice and an increase in the deformation potential scattering, which decreases the mobility of the charge carriers. When the Tb concentration was less than $3 \%$, the effect of ionic radius variation dominated, facilitating both $\mathrm{F}^{-}$ion diffusion and electron transportation. However, when the $\mathrm{Tb}$ concentration was greater than $3 \%$, the increasing deformation potential scattering was dominant, impeding $\mathrm{F}^{-}$ion diffusion and electron transportation.

To comprehensively understand the transport properties of $\mathrm{Tb}$-doped $\mathrm{CaF}_{2}$ nanoparticles, the dielectric properties were further studied. The complex permittivity $\left(\varepsilon^{\prime}, \varepsilon^{\prime \prime}\right)$ with frequency $(f)$ of $\mathrm{CaF}_{2}$ nanocrystals under different $\mathrm{Tb}$ concentrations are shown in Figure 10. 


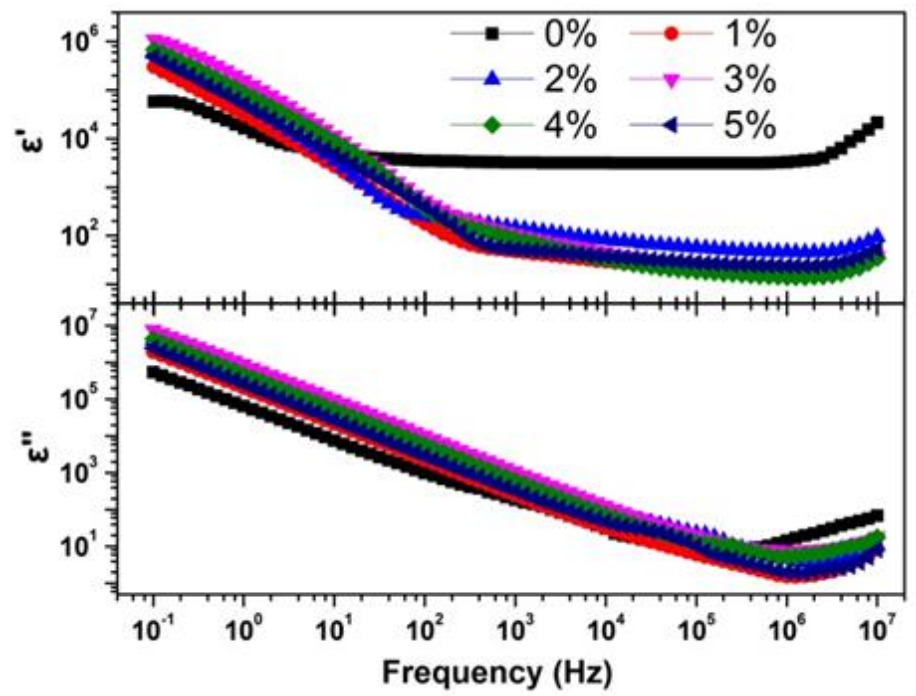

Figure 10. The complex permittivity $\left(\varepsilon^{\prime}\right.$ and $\left.\varepsilon^{\prime \prime}\right)$ vs. the frequency of $\mathrm{CaF}_{2}$ nanocrystals $(f)$ with various $\mathrm{Tb}$ concentrations.

The $\varepsilon^{\prime}$ decreased linearly with increasing frequency in the low frequency region, then remained almost unchanged in the middle frequency region, finally increasing in the high frequency region. The $\varepsilon^{\prime \prime}$ decreased linearly with increasing frequency and then increased in the high frequency region. The presence of strong low-frequency dispersion in the permittivity implies that the electron and ion are hopping in the transport process [30]. At low frequencies, the $\varepsilon^{\prime}$ and $\varepsilon^{\prime \prime}$ of Tb-doped samples were greater than of the un-doped sample, indicating Tb-doping facilitates electron and ion hopping in $\mathrm{CaF}_{2}$ nanocrystals. The substitution of $\mathrm{Ca}^{2+}$ by $\mathrm{Tb}^{3+}$ implies the creation of vacancy. Once a vacancy is created, further atom motion is relatively easy, so a neighboring atom hops into the vacancy, which is easily translated to another site, and finally facilitates charge carriers hopping and increases permittivity.

\section{Conclusions}

$\mathrm{CaF}_{2}$ nanoparticles with various $\mathrm{Tb}$ doping concentrations were characterized by XRD, TEM, and $\mathrm{AC}$ impedance. In all samples, the dominant charge carriers were electrons, and the $\mathrm{F}^{-}$ion transference number increased with increasing $\mathrm{Tb}$ concentration. The defects in the grain region considerably contributed to the electron transportation process. When the $\mathrm{Tb}$ concentration was less than $3 \%$, the ionic radius variation effect dominated and facilitated $\mathrm{F}^{-}$ion diffusion and electron transportation. When the $\mathrm{Tb}$ concentration was greater than $3 \%$, the increasing deformation potential scattering dominated, impeding $\mathrm{F}^{-}$ion diffusion and electron transportation. The substitution of $\mathrm{Ca}^{2+}$ by $\mathrm{Tb}^{3+}$ enabled electron and ion hopping in $\mathrm{CaF}_{2}$ nanocrystals, and finally led to the increasing permittivity. We concluded that rare-earth-doping treatment is an effective method for modulating the electric conductive and dielectric performance of $\mathrm{CaF}_{2}$ nanoparticles. We expect that the design of $\mathrm{CaF}_{2}$-based optical and optoelectronic devices could benefit from our investigation.

Author Contributions: X.C. conceived and designed the experiments; J.W. and Y.C. fabricated and characterized the sample; X.Z. and J.Z. collaborated in XRD, TEM measurements; T.H., X.L., J.Y. and C.G. analyzed the data. All authors discussed the experiment results and contributed to writing the paper.

Funding: This research was funded by [the National Natural Science Foundation of China] grant numbers [11674404, 11704151 and 11404137], [the Program for the development of Science and Technology of Jilin province] grant number [20180101206JC], [Thirteenth Five-Year Program for Science and Technology of Education Department of Jilin Province, China] grant numbers [JJKH20180772KJ and JJKH20180769KJ] and [Open Project of State Key Laboratory of Superhard Materials (Jilin University)] grant number [201710].

Conflicts of Interest: The authors declare no conflict of interest. 


\section{References}

1. Matsuura, D. Red, green, and blue upconversion luminescence of trivalent-rare-earth ion-doped $\mathrm{Y}_{2} \mathrm{O}_{3}$ nanocrystals. Appl. Phys. Lett. 2001, 81, 4526-4528. [CrossRef]

2. Wei, Z.G.; Sun, L.D.; Liao, C.S.; Yan, C.H. Fluorescence intensity and color purity improvement in nanosized $\mathrm{YBO}_{3}:$ Eu. Appl. Phys. Lett. 2002, 80, 1447-1449. [CrossRef]

3. Barber, D.B.; Pollock, C.R.; Beecroft, L.L.; Ober, C.K. Amplification by optical composites. Opt. Lett. 1997, 22, 1247-1249. [CrossRef] [PubMed]

4. Lucca, A.; Jacquemet, M.; Druon, F.; Balembois, F.; Georges, P.; Camy, P.; Doualan, J.L.; Moncorgé, R. High-power tunable diode-pumped $\mathrm{Yb}^{3+}: \mathrm{CaF}_{2}$ laser. Opt. Lett. 2004, 29, 1879-1881. [CrossRef] [PubMed]

5. Kawano, K.; Arai, K.; Yamada, H.; Hashimoto, N.; Nakata, R. Application of rare-earth complexes for photovoltaic precursors. Sol. Energ. Mat. Sol. C 1997, 48, 35-41. [CrossRef]

6. Rothschild, M.; Bloomstein, T.M.; Curtin, J.E.; Downs, D.K.; Fedynyshyn, T.H.; Hardy, D.E.; Kunz, R.R.; Liberman, V.; Sedlacek, J.H.C.; Uttaro, R.S. 157 nm: Deepest deep-ultraviolet yet. J. Vac. Sci. Technol. B 1999, 17, 3262-3266. [CrossRef]

7. Fujihara, S.; Kadota, Y.; Kimura, T. Role of organic additives in the sol-gel synthesis of porous $\mathrm{CaF}_{2}$ anti-reflective coatings. J. Sol-Gel Sci. Technol 2002, 24, 147-154. [CrossRef]

8. McKeever, S.W.S.; Brown, M.D.; Abbundi, R.J.; Chan, H.; Mathur, V.K. Characterization of optically active sites in $\mathrm{CaF}_{2}$ :Ce, Mn from optical spectra. J. Appl. Phys. 1986, 60, 2505-2510. [CrossRef]

9. Fukuda, Y. Thermoluminescence in sintered $\mathrm{CaF}_{2}$ :Tb. J. Radiat. Res. 2002, 43, S67-S69. [CrossRef] [PubMed]

10. Pote, S.S.; Joshi, C.P.; Moharil, S.V.; Muthal, P.L.; Dhopte, S.M. Luminescence of $\mathrm{Ce}^{3+}$ in $\mathrm{Ca}_{0.65} \mathrm{La}_{0.35} \mathrm{~F}_{2.35}$ host. J. Lumin. 2010, 130, 666-668. [CrossRef]

11. Pote, S.S.; Joshi, C.P.; Moharil, S.V.; Muthal, P.L.; Dhopte, S.M. Luminescence in $\mathrm{Ca}_{1-x} \mathrm{Y}_{x} \mathrm{~F}_{2+x}$. Physica B 2011, 406, 1308-1311. [CrossRef]

12. Bensalah, A.; Mortier, M.; Patriarche, G.; Gredin, P.; Vivien, D. Synthesis and optical characterizations of undoped and rare-earth-doped $\mathrm{CaF}_{2}$ nanoparticles. J. Solid State Chem. 2006, 179, 2636-2644. [CrossRef]

13. Hong, B.C.; Kawano, K. Syntheses of euactivated alkaline earth fluoride $\mathrm{MF}_{2}(\mathrm{M}=\mathrm{Ca}$, Sr) nanoparticles. Jpn. J. Appl. Phys. 2007, 46, 6319-6323. [CrossRef]

14. Song, L.; Xue, L. Efficient fluorescence of dissolved $\mathrm{CaF}_{2}: \mathrm{Tb}^{3+}$ and $\mathrm{CaF}_{2}: \mathrm{Ce}^{3+}, \mathrm{Tb}^{3+}$ nanoparticles through surface coating sensitization. Appl. Surf. Sci. 2012, 258, 3497-3501. [CrossRef]

15. Wang, G.; Peng, Q.; Li, Y. Upconversion luminescence of monodisperse $\mathrm{CaF}_{2}: \mathrm{Yb}^{3+} / \mathrm{Er}^{3+}$ nanocrystals. J. Am. Chem. Soc. 2009, 131, 14200-14201. [CrossRef] [PubMed]

16. Zhi, G.L.; Song, J.H.; Mei, B.C.; Zhou, W.B. Synthesis and characterization of $\mathrm{Er}^{3+}$ doped $\mathrm{CaF}_{2}$ nanoparticles. J. Alloy Compd. 2011, 509, 9133-9137. [CrossRef]

17. Zheleznov, D.S.; Starobor, A.V.; Palashov, O.V. Characterization of the terbium-doped calcium fluoride single crystal. Optical Materials 2015, 46, 526-529. [CrossRef]

18. Guo, C.; Gao, F.; Liang, L.; Choi, B.C.; Jeong, J.H. Synthesis, characterization and luminescent properties of novel red emitting phosphor $\mathrm{Li}_{3} \mathrm{Ba}_{2} \mathrm{Ln}_{3}\left(\mathrm{MoO}_{4}\right)_{8}: \mathrm{Eu}^{3+}(\mathrm{Ln}=\mathrm{La}, \mathrm{Gd}$ and $\mathrm{Y})$ for white light-emitting diodes. J. Alloy Compd. 2009, 479, 607-612. [CrossRef]

19. Zhou, L.; Wei, J.; Wu, J.; Gong, F.; Yi, L.; Huang, J. Potential red-emitting phosphor for white LED solid-state lighting. J. Alloy Compd. 2009, 476, 390-392. [CrossRef]

20. Lin, Z.; Liang, X.; Ou, Y.; Fan, C.; Yuan, S.; Zeng, H.; Chen, G. Full color photoluminescence of $\mathrm{Tb}^{3+} / \mathrm{Sm}^{3+}$ codoped oxyfluoride aluminosilicate glasses and glass ceramics for white light emitting diodes. J. Alloy Compd. 2010, 496, L33-L37. [CrossRef]

21. Liang, X.; Yang, Y.; Zhu, C.; Yuan, S.; Chen, G.; Pring, A.; Xia, F. Luminescence properties of $\mathrm{Tb}^{3+}-\mathrm{Sm}^{3+}$ codoped glasses for white light emitting diodes. Appl. Phys. Lett. 2007, 91, 091104. [CrossRef]

22. Zhao, F.; Gao, S. Pyrolysis of single molecular precursor for monodisperse lanthanide sulfide/oxysulfide nanocrystals. J. Mater. Chem. 2008, 18, 949-953. [CrossRef]

23. Chen, M.; Kim, J.; Liu, J.P.; Fan, H.; Sun, S. Synthesis of FePt nanocubes and their oriented self-assembly. J. Am. Chem. Soc. 2006, 128, 7132-7133. [CrossRef] [PubMed]

24. Wang, J.S.; Hao, J.; Wang, Q.S.; Jin, Y.X.; Li, F.F.; Liu, B.; Li, Q.J.; Liu, B.B.; Cui, Q.L. Pressure induced structural transition in $\mathrm{CaF}_{2}$ nanocrystals. Phys. Status Solidi B 2011, 248, 1115-1118. [CrossRef] 
25. Hu, T.; Cui, X.; Wang, J.; Zhong, X.; Chen, Y.; Zhang, J.; Li, X.; Yang, J.; Gao, C. The electrical properties of Tb-doped $\mathrm{CaF}_{2}$ nanoparticles under high pressure. Crystals 2018, 8, 98. [CrossRef]

26. Wang, J.; Yang, J.; Hu, T.; Chen, X.; Lang, J.; Wu, X.; Zhang, J.; Zhao, H.; Yang, J.; Cui, Q. Structural Phase Transition and Compressibility of $\mathrm{CaF}_{2}$ Nanocrystals under High Pressure. Crystals 2018, 8, 199. [CrossRef]

27. Wang, Q.L.; Liu, C.L.; Gao, Y.; Ma, Y.Z.; Han, Y.H.; Gao, C.X. Mixed conduction and grain boundary effect in lithium niobate under high pressure. Appl. Phys. Lett. 2015, 106, 132902. [CrossRef]

28. Ho, C.; Raistrick, I.D.; Huggins, R.A. Application of AC techniques to the study of lithium diffusion in tungsten trioxide thin films. J. Electrochem. Soc. 1980, 127, 343-350. [CrossRef]

29. Ali, A.A. Optical properties of $\mathrm{Sm}^{3+}$-doped $\mathrm{CaF}_{2}$ bismuth borate glasses. J. Lumin. 2009, 129, $1314-1319$. [CrossRef]

30. Peláiz Barranco, A.; Calderón Piñar, F.; Pérez Martínezy, O.; De Los Santos Guerra, J.; González Carmenate, I. AC behaviour and conductive mechanisms of $2.5 \mathrm{~mol} \% \mathrm{La}_{2} \mathrm{O}_{3}$ doped $\mathrm{PbZr}_{0.53} \mathrm{Ti}_{0.47} \mathrm{O}_{3}$ ferroelectric ceramics. J. Eur. Ceram. Soc. 1999, 19, 2677-2683. [CrossRef]

(C) 2018 by the authors. Licensee MDPI, Basel, Switzerland. This article is an open access article distributed under the terms and conditions of the Creative Commons Attribution (CC BY) license (http://creativecommons.org/licenses/by/4.0/). 